\title{
An Investigation of Refusal Strategies as Used by Bahdini Kurdish and Syriac Aramaic Speakers
}

Dilgash M.Shareef*, Marina Isteefan Qyrio, Chiman Nadheer Ali

University of Zakho, Zakho, Duhok, Kurdistan, Iraq

Corresponding Author: Dilgash M.Shareef, E-mail: dilgash.shareef@uoz.edu.krd

\section{ARTICLE INFO}

Article history

Received: December 11, 2017

Accepted: January 24, 2018

Published: February 28, 2018

Volume: 9 Issue: 1

Advance access: January 2018

Conflicts of interest: None

Funding: None

\author{
Key words: \\ Refusal, \\ Kurmanji Kurdish, \\ Sryriac Aramaic. Speech Acts, \\ Requests, \\ Semantic Formulas, \\ Discourse Completion Task (DCT)
}

\begin{abstract}
For the purpose of achieving a successful communication, issues such as the appropriateness of speech acts and face saving become essential. Therefore, it is very important to achieve a high level of pragmatic competence in speech acts. Bearing this in mind, this study was conducted to investigate the preferred refusal strategies Kurdish and Syriac native speakers use when faced with offers and requests from equal status interlocutors. The current study has used a modified Written Discourse Completion Test (WDCT) consisting of six situations (three of which elicit refusals to offerings and the other three to requests). Forty subjects participated in this study: 20 native speakers of the Kurdish language (10 male and 10 female students) and 20 native speakers of Syriac language (10 male and 10 female students). All participants are currently pre-graduate students attending Zakho University. The participants were asked to provide written data that express their refusals to these situations. The data collected have then been analyzed descriptively according to frequency and number of occurrences of semantic formulas used by Beebe et al (1990). The results showed that a) the Syriac Native Participants (SNP)s frequently preferred indirect and adjunct strategies for refusals rather than direct ones, b) the Kurdish Native Participants (KNP)s often preferred direct and indirect strategies more than adjunct ones, c) the results also revealed that gender has a great influence on the use of refusal strategies in various ways. Finally, this study concludes that both KNPs and SNPs tended to use more strategies when refusing requests than offers whereas gender has shown to play a significant role in the choice and number of the refusal strategies used by both groups of participants.
\end{abstract}

\section{INTRODUCTION}

Different definitions have been given to the term of speech act. Searl (1969) defines the term as a minimal unit of discourse whereas Cohen (1995) defines it as a basic and functional unit of communication.

Tanck (2003) found out that speakers tend to use various speech acts to achieve their communicative goals, including Searle's seminal broad categories that consist of: directives (e.g. requests, commands), commissives (e.g. promises, threats), representatives (e.g. assertions, claims), declaratives (e.g. declaring war), and expressives (e.g. apologies, thanks). The focus of this study, the speech act of refusal, belongs to the category of expressives.

Speech act strategies in different languages and across a number of languages and cultures have been intensively investigated over the last thirty years. Increased attention, however, has been particularly given to the speech act of refusal as it is one of the most commonly-used speech act in everyday communication. Refusal has been investigated in various languages as Arabic (Abdul Sattar, Che Lah, \& Raja Suleiman, 2010; Al-Eryani, 2007; Al-Issa, 1998, 2003; Al-Kahtani, 2005; Al-Shalawi, 1997; Morkus, 2009; Nelson,
Carson, Al Batal, \& El Bakary, 2002), Persian (Allami \& Naeimi, 2011; Sadeghi \& Savojbolaghchilar, 2011). These studies were all aimed to arrive at an understanding of how human communication is carried out through linguistic behavior.

\section{Speech act of Refusal}

Searle and Vandervken (1985, p.195) define the speech act of refusal as follows: "the negative counterparts to acceptances and consentings are rejections and refusals. Just as one can accept offers, applications, and invitations, so each of these can be refused or rejected". In other words, a refusal is realized when a speaker "denies to engage in an action proposed by the interlocutor" (Chen et al., 1995:121).

According to Brown and Levinson (1987) the speech act of refusal is considered as a potential face-threatening act because the risk of offending the addressee is inherent in the act itself.

For Beebe et al. (1990), refusal is a complex speech act to realize because it needs a high level of pragmatic competence to be performed effectively. This speech act usually requires the use of indirect strategies to minimize the offense to the hearer. 
Additionally, a refusal is characterized as a high-risk speech act since failure to refuse appropriately might jeopardize the personal relations between the speakers (Allami and Naeimi, 2011; Kwon, 2003). For this reason, this speech act has been found to play a major role in causing miscommunication and misunderstanding among speakers.

Refusals are found in four types of exchanges, namely those involving invitations- refusals, requests-refusals, offers-refusals and suggestions-refusals. The type of initiate act influences the realization of both the content and the form of refusal in question. This study focuses on refusals of offers and refusals of requests only.

\section{Kurdish and Syriac Languages}

According to Haig \& Yaron, (2002), Kurdish belongs to Northwest Iranian languages and it is a cover term for a bundle of closely-related Iranian dialects that is spoken across a large area of Turkey, Iraq, and Iran, smaller communities of Kurds also live in Syria, Armeniya and Azerbijan. Additionally, Kurdish language is a member of the Indo-Iranian family of the Indo-European languages (Salavati and Esmaili,2013).

Kurdish language is also rich in dialects. The largest and most spoken dialect, however, is Kurmanji, which is often referred to as Bahdini. This dialect has, until recently, been written in a modified Arabic/Persian script. The Kurdish alphabets used in this paper are based on the Arabic/Persian script: See (Appendix A) for table by Salavati and Esmaili (2013) including the Kurdish alphabets used in this paper.

The other language that is investigated is Aramaic which is a member of the Semitic subfamily of the Afro Asiatic language family and forms one of the two main branches of the Northwest Semitic group within that family, the other being Canaanite (comprising Hebrew, Phoenician, Moabite, etc.). The language most closely related to Aramaic is Hebrew (Woodard,2008). More distantly related languages include Akkadian and Arabic. The Aramaic language is usually subdivided into five historical stages and contemporaneous dialects: Ancient, Official, Middle, Late and Modern. Syriac is the local dialect of the Aramaic that has appeared during the Middle stage (200BC-AD200) and it is the dialect that is widely used in Northern Iraq, i.e. Iraqi Kurdistan region. The Syrica scripts used in this paper are found in (Appendix B).

\section{Research Aim and Questions}

Iraqi Kurdistan is a hugely trilingual community. Along with the formal language of Kurdish which is the first language of the vast majority of its residents, two other local languages are at work: Arabic and Syriac. This lingual diversity often leads to daily communication and interaction among members of these different languages. However, native-Arab speakers are rarely seen attempting to speak Kurdish because many Kurds residing in Iraqi Kurdistan can perfectly speak Arabic as a second language and therefore speakers of Arabic need not speak or learn Kurdish, unlike Syriac Aramaic speakers who often shift to Kurdish for a daily commu- nication with Kurds. The Syriac speakers of Kurdish, however, often encounter difficulties in choosing the appropriate strategies when they converse in Kurdish and this, in turn, affects the success of communication among Kurdish and Syriac speakers. For this reason, the present study aimed to describe and compare the strategies employed in refusing requests and offers by Bahdini Kurdish speakers and Syriac Aramaic speakers in the hope that the Syriac speakers of Kurdish have a better grasp of the refusal strategies used by the native Bahdini Kurds.

Furthermore, the study aimed to examine the effect of gender on the choice of the offer and request refusal strategies by the two groups of Kurdish and Syriac speakers. Put it in the nutshell, the present study attempts to answer the following questions:

1. What are the frequent strategies used by the native speakers of the Syriac Aramaic language in refusing offers and requests?

2. What are the frequent strategies used by the native speakers of the Bahdiny dialect of Kurdish language in refusing offers and requests?

3. Do Kurdish and Syriac Aramaic speakers use similar or different strategies in making refusals?

4. Does gender play any role in the choice of refusal strategies used by the Kurdish and Syriac Aramaic participants of the current study?

\section{LITERATURE REVIEW}

\section{Refusal Studies}

The relevant literature for refusal is very rich mainly after the publication of Beebe, et. al (1990) who made a comparison between the refusals given by native speakers of Japanese and English natives through the use of a DCT composed of 12 items. The study came up with huge differences between Americans and Japanese in the order, frequency, and content of semantic formulas in refusals. Each used a different strategy for refusals; Japanese based on the social status of interlocutors while Americans on the degree of familiarity or the social distance from the interlocutors.

Ramos (1991) led a study that aimed to describe the patterns, forms, rules, and strategies (sociolinguistic behavior) used by Puerto Rican speakers of Spanish in refusing requests, invitations and offers.

The study also compared and contrasted refusals of Puerto Rican speakers of Spanish with native speakers of American English. The findings arrived at revealed that refusals among Puerto Rican teenagers with low proficiency in English tended to be shorter, simpler and more direct than refusals by native speakers of American English.

Among the studies conducted on Arabic, Stevens (1993) used a written DCT composed of 15 situations: 8 requests and 7 offers/invitations to study Arabic and English refusals. Stevens' results indicated that Arab and English speakers followed many similar strategies.

Abdul Sattar et. al. (2011) investigated the preferred semantic formulas used in refusing suggestions by Iraqi-speaking Arabs living in Malaysia. They found that Iraqis em- 
ployed some preferred types of refusal indirect patterns when refusing a suggestion. For example, they used "No" followed by explanation. This might indicate that they tend to be rude and risk of losing other's face when using negative ability and willingness. The researchers, however, stated that the subjects' refusals were always softened and justified by giving reasons, explanations and other indirect strategies like using openers (or semantic adjuncts) to define the relationships, apologies, etc.

\section{Refusal Studies in Kurdish and Syriac}

The relevant literature of Kurdish native speakers' refusals is not as rich as other cultures or nations and most of these studies are mainly done by native Kurdish linguists. In fact, the field of refusal act has been neglected to an extent in Kurdish language. Aliakbari and Changizi (2012) in their study "On the realization of refusal strategies by Persian and Kurdish speakers" studied the use of refusal by Persian and Kurdish speakers (PSs and KSs) with a particular focus on the frequency and shift of semantic formulas with regard to types of eliciting acts and status of the interlocutor. The investigation included 136 PSs and $142 \mathrm{KSs}$. They were asked to fill out a written (DCT). The findings of the study indicated that 'direct refusal', 'regret', 'excuse and reason', 'wish', and 'postponement' were the most frequently used strategies. Furthermore, big differences were observed in the frequency and shift of semantic formulas used by PSs and KSs.

Khalil (2014) in his "A study of Refusal Strategies in Kurdish language" attempted to investigate the strategies used by Kurdish university students in refusing offers and requests and whether or not the gender would have any influence on the choice and number of refusal strategies. The conclusions arrived at indicate that Kurdish male and female participants have employed different strategies with different semantic formulas in refusing offers and requests.

Mustafa and Moheddin (2016) in their investigation "Invitation's Refusal Strategies in Kurdish" concentrate on the analysis of the linguistic means used by Kurdish people to refuse invitations; illustrating how Kurdish people realize the speech act of refusals when the refuser is lower, equal, or higher in status to the refusee. The purpose of their study was to discover the ways of performing refusals since they are sensitive to social or cultural variables. The participants in this study were twelve Kurdish male university students and professors as well. Throughout this study, the researchers reached to the following findings that performing refusals is a face threatening act. The direct strategy in refusing invitations from someone of lower status (i.e. students) was most valued by professors. However, they expressed [Gratitude] in their responses as a way to sound polite, save the inviter's face and show respect and appreciation to the student's good will. Additionally, Kurdish professors did not express [Regret] to their inviters. Moreover, indirect strategies were employed by respondents when refusing individuals of higher and equal status. In addition to this, Kurds are appeared to be rank-conscious. To recognize the higher social rank of their interlocutors, they (i.e. lower status participants) used the [addressing term] 'professor' as a way to show respect. It was revealed that the use of refusal strategies varied according to the status of the inviter.

As far as refusal studies on Syriac Aramaic are concerned, to the best of the authors' knowledge, there has not been any earlier investigation in this face threatening act. Therefore, the current study is attempting to examine and then compare the refusal strategies employed in refusing requests and offers by Syriac and Kurdish speakers living in the same community.

\section{METHOD}

\section{Participants}

Forty subjects participated in this study: 20 Kurdish native participants (henceforth KNPs) (10 males and 10 females), and 20 Syriac native participants (henceforth SNPs) (10 males and 10 females). Both groups were University-level students attending Zakho University in the academic year 2016-2017. The range of ages of the subjects was 20-24. Finally, it is important to state that both groups of participants came from two major cities in Iraqi Kurdistan: Duhok and Zakho.

\section{Data Collection}

The Written Discourse Completion Task (WDCT) procedure was used to obtain the refusal data. It took the form of a written questionnaire consisting of incomplete responses. The original WDCT was written in English language and it was translated into the Syriac Aramaic and Kurdish language to be given to the speakers of the two languages in questions, see appendices (C, D, E). The WDCT consisted of six different situations -three of which elicited refusals to offerings and the other three to requests. The situations were selected from everyday life situations that might happen in any time. The relationship between the speaker and the interlocutor was equal. It is worth mentioning that all participants of this study are permanent residents of Iraqi Kurdistan with the Syriac participants speaking Kurdish as a second language.

\section{Data Analysis}

The data collected from the two groups were analyzed form two standpoints. First, the semantic formulas were coded as 'direct refusals', 'indirect refusals' and 'adjuncts to refusals' based on the Beebe et al. (1990) classification system. This procedure helped to figure out the refusal strategies used by each group and thus it provided answers for the first two questions of the study. Second, in the light of the same classification system but with additional categories put forward by Beebe et al. (1990), the refusal responses given by the participants were analyzed as consisting of sequences of semantic formulas. Then, the responses of the two groups were compared to each other to discover to what extent the KNPs differed from or were similar to SNPs in making refusals to requests and offers. Finally, the responses made by male and female participants within each group were compared 
to each other to reveal the possible role played by gender differences in refusing requests and offers.

Regarding the first two questions of the current study, it has been observed that both Syriac and Kurdish participants used a wide range of refusal strategies. The following subsections describe the strategies used by both groups in details, starting first with the strategies made by SNPs and then followed by the ones employed by KNPs.

\section{Refusal Strategies Used by Syraic Native Participants (SNPs)}

The total strategies made by SNP participants are (376) with males using (162) refusal strategies at $(\% 43.08)$ and females employing (214) refusal strategies (\%56.9).

SNPs used (251) direct refusal strategies at $(\% 66.75)$ while (345) for indirect strategies at (\%91.75). SNP males used 156 indirect strategies while (189) indirect strategies were used by females. These numbers and percentages show that the indirect strategies are a more preferred strategy among SNPs. Below is a detailed analysis of the refusal strategies employed by SNPs when refusing offers and requests with a particular emphasis on the responses made by male and female participants because gender is used as a variable to answer the third question of this study.

\section{The Strategies Used in Refusing Offers by Syriac Male and Female Native Participants}

To begin with, the first situation in the WDCT requires the respondent's refusal of an offer made by his/her friend to drink something. The second situation requires the respondent to refuse an offer made by his/her friend to use his/her phone. The third situation requires the respondent to refuse an offer to help his/her friend in carrying some bags. The respondents were asked to refuse these three offers. Regarding the Syriac native participants (SNPs), all offer written refusal responses obtained from them resulted in (145) refusal strategies.

For refusal strategies used by males, (64) different strategies were used in refusing the offers. The strategies were a mixture of direct, indirect and refusal adjuncts. It has been found that the adjunct of gratitude (e.g." thank you very

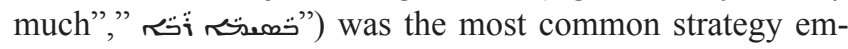
ployed by the participants in approximately $43.8 \%$ of the strategies $(n=28)$.

Excuse/reason/explanation (e.g. "I drunk before awhile","مi:") was found to be the second most frequent strategy mentioned in approximately $29.7 \%$ of the strategies $(n=19)$. Postponement (e.g. "I will call later", " came to be the third most frequent strategy mentioned in approximately $15.6 \%$ of the strategies $(\mathrm{n}=10)$.

The remaining strategies: negative willingness/ability, statement of regret, and let the interlocutor off the hook were mentioned twice and thus account for $3.1 \%$ respectively. Usingidioms(e.g. "fromthebottomofmyheart"," حصف "لكلص:")was the last strategy used by the participants in approximately $1.6 \%$ of the strategies $(n=1)$.
For refusal strategies used by females, (81) different strategies were used in refusing the offers. It has been found that the adjunct of gratitude was the most frequent strategy used by the participants in approximately $37.1 \%$ of the strategies $(n=30)$. Excuse/reason/explanation was the second most frequent strategy mentioned in approximately $32.1 \%$ of the strategies $(n=26)$. Negative willingness/ability (e.g. "I cannot"," لبs (")" was the third most frequent strategy mentioned in approximately $9.9 \%$ of the strategies $(n=8)$. Postponement was the fourth most frequently used strategy in approximately $6.17 \%$ of the strategies $(n=5)$. Let the inter-

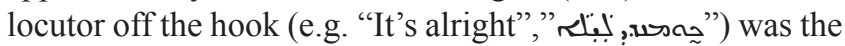
fifth most frequent strategy used in approximately \%4.9 of the strategies $(n=4)$. Statement of negative consequences (e.g. "Believe me I really would like to but...

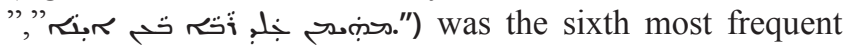
strategy mentioned in approximately $\% 3.7$ of the strategies $(n=3)$. Statement of regret and Statement of positive opinion/ feeling or agreement (e.g. "I'd love to believe

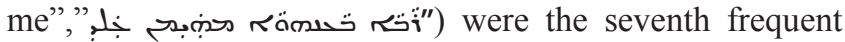
strategies mentioned in approximately $\% 2.5$ of the strategies $(n=2)$. Set condition for future or past acceptance (e.g. "Be sure that if you had asked me earlier, I would have.",

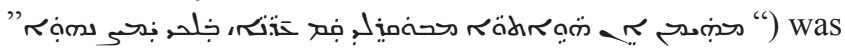
the last strategy mentioned in approximately $\% 1.2$ of the strategies $(n=1)$.

\section{The Strategies Used in Refusing Requests by Syriac Male and Female Native Participants}

The respondents were asked to refuse three requests. The first situation in the WDCT requires the respondent's refusal of a request made by his/her friend to lend him/her $50 \$$. The second situation requires the respondent to refuse a request made by his/her friend to lend his/her class notes to a classmate. The third situation requires the respondent to refuse a request to help his/her friend in getting the library books back instead of him/her. Concerning the Syriac native participants (SNP), all written request refusal responses obtained from them resulted in (231) refusal strategies.

For refusal strategies used by males, 98 strategies were used in refusing the requests. The strategies were a mixture of direct, indirect and adjuncts. It has been found that excuse/reason/explanation (e.g. "I need to study for the exam as well","

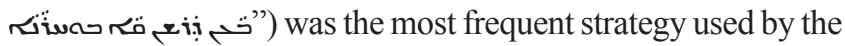
participants in approximately $\% 30.2$ of the strategies $(n=30)$. Ask for forgiveness (e.g. "I ask forgiveness from you", "for-

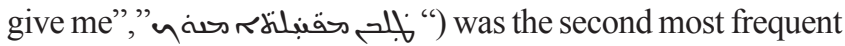
strategy mentioned in approximately \% 21.4 of the strategies $(n=21)$. Statement of regret (e.g. "I'm sorry, believe me...","

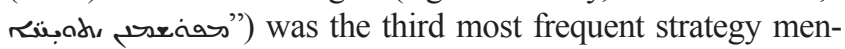
tioned in approximately $\% 11.2$ of the strategies $(n=11)$. Statement of empathy (e.g. "My brother/sister, I realize that you are

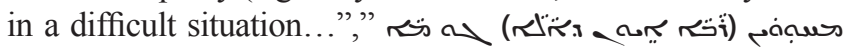

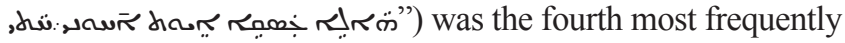
used strategy in approximately $\% 6.1$ of the strategies $(n=6)$.Set condition for future or past acceptance and define relation strategies were the fifth most frequently used strategies in approximately $\% 5.1$ of the strategies $(n=5)$.Negative willingness/abil- 
ity was the sixth frequently used strategy in approximately $\%$ 4.1 of the strategies $(n=4)$. Statement of alternative (e.g. "Why

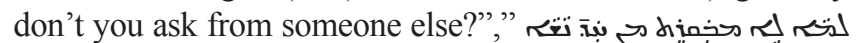
" ") and postponement (e.g. "Maybe later", "leave it for

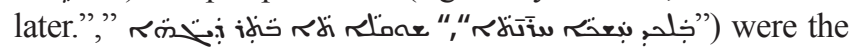
seventh used strategies in approximately $\% 3.1$ of the strategies $(n=3)$. Statement of negative consequences and getting the interlocutor's attention (e.g. "Look brother/sister", "listen to

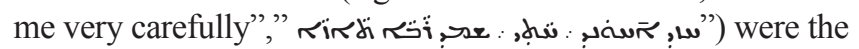
eighth used strategies in approximately $\% 2.4$ of the strategies $(n=2)$. The remaining strategies: promise of future acceptance

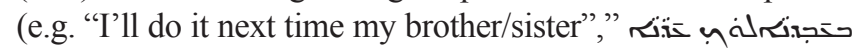

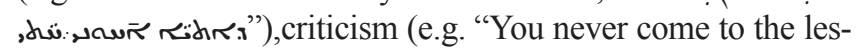

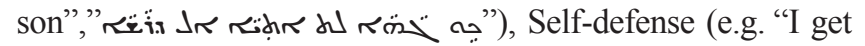
tired and take a lot of time making my notes", "I attend regular-

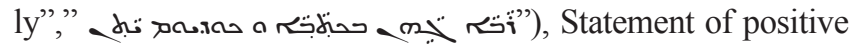
opinion/feeling or agreement, apology, and request for understanding were the last used strategies in approximately $\% 1.1$ of the strategies $(n=1)$.

For refusal strategies used by females, (133) different strategies were used in refusing the requests. It has been found that excuse/reason/explanation was the most frequent strategy used by the participants in approximately \% 25.6 of the strategies $(n=34)$. Ask for forgiveness was the second most frequent strategy mentioned in approximately \%15.8 of the strategies $(n=21)$. Negative willingness/ability was the third frequently used strategy in approximately $\% 12.8$ of the strategies $(n=17)$. Statement of regret was the fourth most frequent strategy mentioned in approximately $\% 9.8$ of the strategies $(n=13)$.Statement of empathy was the fifth most frequently used strategy in approximately $\% 6.8$ of the strategies $(n=9)$. Statement of negative consequences was the sixth used strategy in approximately $\% 6.1$ of the strategies $(n=8)$. Statement of positive opinion/feeling or agreement was the seventh used strategy in approximately $\% 4.5$ of the strategies $(n=6)$.Statement of alternative, set condition for future or past acceptance, and request for understanding were the eighth used strategies in approximately $\% 3.1$ of the strategies $(n=4)$. Getting the interlocutor's attention was the ninth used strategy in approximately $\% 2.3$ of the strategies $(n=3)$. Wish, postponement, criticism, self-defense were used twice in approximately $\% 1.5$ of the strategies. Promise of future acceptance and using idioms were the last strategies used in approximately $\% 0.8$ of the strategies $(n=1)$. Table (1) below provides a better illustration of the strategies used by SNPs.

\section{Refusal Strategies Used by Kurdish Native Participants (KNPs)}

Concerning the total number of the refusal strategies that were employed by (KNPs), (299) refusal strategies were the results of the current investigation. Male participants used (163) refusal strategies at $(\% 54.1)$, on the other hand (136) refusal strategies were employed by female participants at (\%45.5).

As it has been acknowledged in the previous part (Section 4.2), the KNPs have used a great variety of strategies consisting of direct, indirect, and adjuncts. males used (36) direct strategies at $(\% 22.1),(102)$ indirect strategies at (\%62.6), and (25) adjuncts at (\%15.3). On the other side, females used (27) direct strategies at (\%19.6),(86) indirect strategies at (\%63.2), and (23) adjuncts at (\%16.9). These numbers and percentages indicate that the KNPs are similar to their SNPs counterparts in their preferences for the use of indirect strategies.

\section{The Strategies Used in Refusing Offers by Kurdish Male and Female Native Participants}

Concerning the refusal strategies that were used by KNP males, totally, 83 different strategies were employed when refusing offers. The strategies were a mixture of Direct, Indirect, and Adjunct. The gathered data also indicated that, the adjunct refusal of "Gratitude" (e.g."Thanks, "سوناس) was the most frequently used strategy by Kurdish male participants approximating $\% 25.3$ of the strategies $(n=21)$.

Non-performative (e.g. "No", “ن”) was the second most frequently used strategy roughly $\% 24.1$ of the strategies $(n=20)$. Reason/explanation/excuse (e.g. "They are not heavy"نة يَت طر انن"Ras considered the third most frequent strategy mentioned approximately \% 21.7 of the strategies $(n=18)$.Let the interlocutor off the hook (e.g. "It does not need", "ثنتظى ناكت was the fourth most regularly used strategy roughly \% 14.5 of the strategies $(n=12)$.Postponement(e.g. "I will call him later”, “ثناثشى ديَ نة لة فونىَ بو كة م") was the fifth most frequently used strategy approximately \% 4.8 of the strategies $(n=4)$. Regret (e.g. "Sorry ", “بورة "

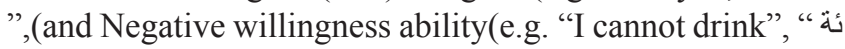
(and statement of alternative ("I will charge my phone”, “"دئَ تة لة فونا خو شة حن كم" were the sixth most regularly used strategies roughly \% 2.4 of the strategies $(n=2)$.Both strategies Swearing (e.g. "I swear to God", "ب

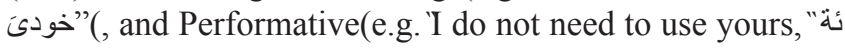
ئن ") were the last strategies used by male participants approximately \% 1.2 of the strategies $(n=1)$.

Regarding the total number of strategies that were used by female participants in refusing offers, 65 strategies were employed. From the data that were gathered, it has been obvious that the adjunct refusal of Gratitude (e.g. "Thank you very much ", (was the most preferred and frequently used strategy that roughly $\% 30.8$ of the strategies $(n=20)$. Reason/explanation/excuse (e.g. 'I have drunk before a while "بة رى بيَهنةكيَ من ياظة خارى", (was the second most frequently used strategy approximately \% 23.1 of the strategies $(n=15)$. Non-performative (e.g. "No ", "ننة, نـة خيَر was the third most preferred strategy roughly \% 16.9 of the strategies $(n=11)$.Let the interlocutor off the hook (e.g. " It is ok ", ضنينة ", "It does

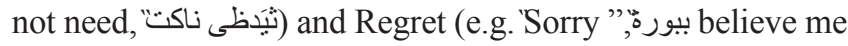
" (were found to be the fourth most frequently used strategy approximately $\% 7.7$ of the strategies $(n=5)$.

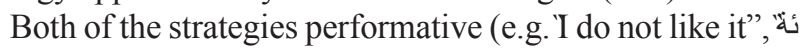
"I ئة ز بكار نائينج", "I will not use it, and negative consequences (e.g. ". But I do not think she will pick up strange

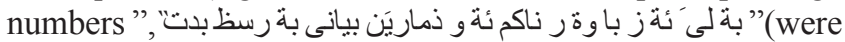
the sixth most regularly used strategies that approximately \% 4.6 of the strategies $(n=3)$.Postponement(e.g. 'I will call her later ", دون ثناش بو كة ")" (was mentioned twice \%3.1.Finally,

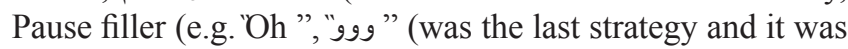
used only once $\% 1.5$. 
Table 1. The semantic formulas used by male and female SNPs for offers and requests

\begin{tabular}{|c|c|c|c|c|c|c|c|c|}
\hline \multirow{3}{*}{$\begin{array}{l}\text { Semantic formula } \\
\text { Negative willingness/ability }\end{array}$} & \multicolumn{4}{|c|}{ Offer ( No. \%) } & \multicolumn{4}{|c|}{ Request (No. \%) } \\
\hline & \multicolumn{2}{|c|}{ Males } & \multicolumn{2}{|c|}{ Females } & \multicolumn{2}{|c|}{ Males } & \multicolumn{2}{|c|}{ Females } \\
\hline & 2 & 3.1 & 8 & 9.9 & 4 & 4.1 & 17 & 12.8 \\
\hline Statement of regret & 2 & 3.1 & 2 & 2.5 & 11 & 11.2 & 13 & 9.8 \\
\hline Wish & 0 & 0 & 0 & 0 & 0 & 0 & 2 & 1.5 \\
\hline Excuse, reason, explanation & 19 & 29.7 & 26 & 32.1 & 30 & 30.2 & 34 & 25.6 \\
\hline Statement of alternative & 0 & 0 & 0 & 0 & 3 & 3.1 & 4 & 3.1 \\
\hline Set condition for past/future acceptance & 0 & 0 & 1 & 1.2 & 5 & 5.1 & 4 & 3.1 \\
\hline Promise for future acceptance & 0 & 0 & 0 & 0 & 1 & 1.1 & 1 & 0.8 \\
\hline Postponement & 10 & 15.6 & 5 & 6.17 & 3 & 3.1 & 2 & 1.5 \\
\hline Criticism & 0 & 0 & 0 & 0 & 1 & & 2 & 1.5 \\
\hline Negative consequences & 0 & 0 & 3 & 3.7 & 2 & 2.4 & 8 & 6.1 \\
\hline Self defense & 0 & 0 & 0 & 0 & 1 & 1.1 & 2 & 1.5 \\
\hline Let the interlocutor of the hook & 2 & 3.1 & 4 & 4.9 & 0 & 0 & 0 & 0 \\
\hline Ask for forgiveness & 0 & 0 & 0 & 0 & 21 & 21.4 & 21 & 15.8 \\
\hline Apology & 0 & 0 & 0 & 0 & 1 & 1.1 & 0 & 0 \\
\hline Request for understanding & 0 & 0 & 0 & 0 & 1 & 1.1 & 4 & 3.1 \\
\hline Define relation & 0 & 0 & 0 & 0 & 5 & 5.1 & 0 & 0 \\
\hline Using idioms & 1 & 1.6 & 0 & 0 & 0 & 0 & 1 & 0.8 \\
\hline Statement of positive opinion/agreement & 0 & 0 & 2 & 2.5 & 1 & 1.1 & 6 & 4.5 \\
\hline Statement of empathy & 0 & 0 & 0 & 0 & 6 & 6.1 & 9 & 6.8 \\
\hline Gratitude/appreciation & 28 & 43.8 & 30 & 37.1 & 0 & 0 & 0 & 0 \\
\hline $\begin{array}{l}\text { Getting the interlocutor's } \\
\text { Attention }\end{array}$ & 0 & 0 & 0 & 0 & 2 & 2.4 & 3 & 2.3 \\
\hline Total & 64 & 39.5 & 81 & 37.9 & 98 & 60.5 & 133 & 62.2 \\
\hline
\end{tabular}

\section{The Strategies Used in Refusing Requests by Kurdish Male and Female Native Participants}

For the refusal strategies that were employed by Kurdish native participants (KNP) in refusing requests, totally 151 refusal strategies were used. Regarding the refusal strategies that were used by male participants, totally, 80 different strategies were employed when refusing requests. The strategies were mixture of Direct, Indirect, and Adjunct. Throughout analyzing the data, it became obvious that the indirect refusal of Regret (e.g. 'Sorry ", ببورة" (was the most frequently used strategy that approximately \% 32.5 of the strategies $(n=26)$.Reason/excuse/explanation(e.g. I am very busy (was the second most preferred strategy that was roughly \% 30 of the strategies $(n=24)$. The third most frequent used strategy is negative willingness ability(e.g.I cannot ", بئة نة شيَح " that approximately \% 10 of the strategies $(n=8)$.Non-performative (e.g. No ", '“(was considered as the fourth most regularly used strategy roughly $\%$ 6.25 of the strategies $(n=5)$.

Both of the strategies criticize the interlocutor (e.g. You should have attended the classes too ", ظيابا تو ذى هاتباى دو اناندا" ”), and swearing (e.g. 'I swear to God "ب خودئ" (were the fifth most preferred strategies and they were approximately $\% 3.75$ of the strategies $(n=3)$. The coming three strategies statement of positive opinion(e.g. 'I would help you", دا د", statement of empathy (e.g. "do not be sad ”,

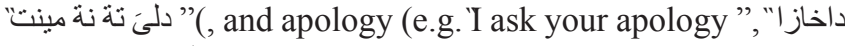

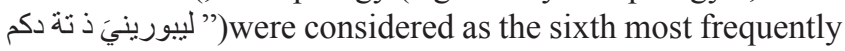
used strategies that approximately \% 2.5 of the strategies $(n=2)$.All of the remaining strategies (wish/promise of future acceptance//Idiom/define relation/and asking for forgiveness)were the last strategies used by the male participants in refusing requests and all of them were used only for one time $\% 1.3$.

The total number of the refusal strategies employed by femal participants in refusing requests was 71 . Additionally, the strategies were mixture of direct, indirect, and adjunct. The results of the data indicated that both strategies regret

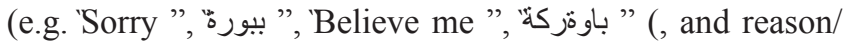

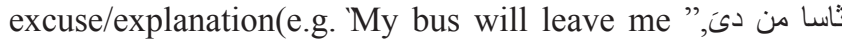

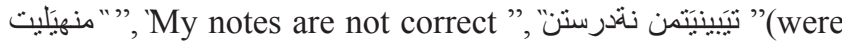
the most frequent used strategies that approximately \% 29.6 of the strategies $(n=21)$.

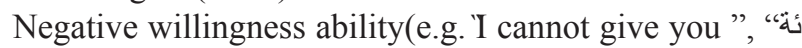
"Was the second most preferred strategy roughly $\% 12.7$ of the strategies $(n=9)$.Both of the strategies negative consequences (e.g. "Actually I really wanted to give you

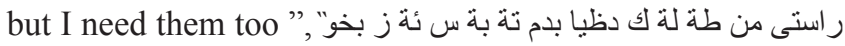
"ذّى محتاجم" (, and criticize the interlocutor (e.g. You should have attended your classes ", 'ظيابا تو هاتباى د محازريَت خودا" '" were considered as the third most regularly used strategies that were approximately \% 5.6 of the strategies $(n=4)$. 
Non- performative (e.g. No ","نة نة خيَرَ'(was the fourth most preferred strategy that roughly $\% 4.2$ of the strategies $(n=3)$. Both of the strategies set condition for future acceptance (e.g. If I had it "هة كة ر هة با "ها" (e.g. On my eyes, " سة رضاظا" (were the fifth most frequent used strategies and approximately $\% 2.8$ of the strategies $(n=2)$.Concerning all of the remaining strategies (performative/promise of future acceptance/statement of positive opinion/statement of empathy/and statement of alternative) were the last strategies employed by female participants and as all of them were used only once. The overall semantic formulas used by Kurdish participants are given in Table (2) below:

\section{A COMPARISON OF STRATEGIES}

In this part, the similarities and the differences of the speech act of refusals between Syriac and Kurdish participants will be investigated in order to provide answers for the third research question that was formulated. Firstly, a number of similarities were observed between SNPs and KNPs. One of the similar points was that (excuse/reason/explanation, statement of regret, gratitude/appreciation, and negative willingness ability) were the most frequent strategies used by both SNPs and KNPs. As it is illustrated in Table (3), excuse/reason, and explanation was the refusal strategy most frequently used by both Syriac and Kurdish participants Moreover, another similar point that is shared between both SNPs and
KNPs is that the indirect strategy was the most preferred one among them. Additionally, as it is mentioned in Table (4) both the SNPs and the KNPs were noticed to use a larger number of strategies in the case of refusing requests than in case of offers.

Aside from these similarities, there were a number of differences between the refusal strategies used by SNPs and KNPs. For example, SNPs and KNPs were shown to use different frequency and variety of the refusal strategies. SNPs were found to use a greater variety of strategies compared with KNPs. In addition to this, the findings of this investigation revealed that the SNPs used more adjunct refusal strategies than KNPs as shown in Table (5). On the other side; KNPs employed more direct refusal strategies than SNPs. Moreover, a significant difference was found between the two groups in using the direct refusal strategies. The direct refusal "NO" and the per formative direct refusal statement "I refuse", were employed by KNPs, while those strategies were never mentioned by the SNPs. There was a big difference in the application of the semantic formulas of 'swearing', and "pause filler" between the two groups. The KNPs tended to employ them whereas the SNPs have never used them. On the contrary, the SNPs employed the refusal strategies of "getting the interlocutor's attention" and "request for understanding" while the KNPs did not seem to use them. Finally, the Syriac participants differed from the Kurdish participants in their use of the refusal strategy of

Table 2. The semantic formulas used by male and female KNPs for refusing offers and requests.

\begin{tabular}{|c|c|c|c|c|c|c|c|c|}
\hline \multirow{3}{*}{$\begin{array}{l}\text { Semantic formulas } \\
\text { Per formatives }\end{array}$} & \multirow{2}{*}{\multicolumn{4}{|c|}{$\begin{array}{l}\text { Offer (No. \%) } \\
\text { Males Females }\end{array}$}} & \multirow{2}{*}{\multicolumn{4}{|c|}{$\begin{array}{c}\text { Request (No. \%) } \\
\text { Males Females }\end{array}$}} \\
\hline & & & & & & & & \\
\hline & 1 & 1.2 & 3 & 4.6 & 0 & 0 & 1 & 1.4 \\
\hline Non-per formative & 20 & 24.1 & 11 & 16.9 & 5 & 6.3 & 3 & 4.2 \\
\hline Negative willingness/ability & 2 & 2.4 & 0 & 0 & 8 & 10 & 9 & 12.7 \\
\hline Statement of regret & 2 & 2.4 & 5 & 7.7 & 26 & 32.5 & 21 & 29.6 \\
\hline Wish & 0 & 0 & 0 & 0 & 1 & 1.3 & 0 & 0 \\
\hline Excuse, reason, explanation & 18 & 21.7 & 15 & 23.1 & 24 & 30 & 21 & 29.6 \\
\hline Statement of alternative & 2 & 2.4 & 0 & 0 & 0 & 0 & 1 & 1.4 \\
\hline Set condition for past/future acceptance & 0 & 0 & 0 & 0 & 0 & 0 & 2 & 2.8 \\
\hline Promise of future acceptance & 0 & 0 & 0 & 0 & 1 & 1.3 & 1 & 1.4 \\
\hline Postponement & 4 & 4.8 & 2 & 3.1 & 0 & 0 & 0 & 0 \\
\hline Criticism & 0 & 0 & 0 & 0 & 3 & 3.6 & 4 & 5.6 \\
\hline Statement of negative consequences & 0 & 0 & 3 & 4.6 & 0 & 0 & 4 & 5.6 \\
\hline Let the interlocutor off the hook & 12 & 14.5 & 5 & 7.7 & 0 & 0 & 0 & 0 \\
\hline Ask for forgiveness & 0 & 0 & 0 & 0 & 1 & 1.3 & 0 & 0 \\
\hline Apology & 0 & 0 & 0 & 0 & 2 & 2.5 & 0 & 0 \\
\hline Define relation & 0 & 0 & 0 & 0 & 1 & 1.3 & 0 & 0 \\
\hline Using idioms & 0 & 0 & 0 & 0 & 1 & 1.3 & 2 & 2.8 \\
\hline Statement of positive opinion/agreement & 0 & 0 & 0 & 0 & 2 & 2.5 & 1 & 1.4 \\
\hline Statement of empathy & 0 & 0 & 0 & 0 & 2 & 2.5 & 1 & 1.4 \\
\hline Gratitude/appreciation & 21 & 25.3 & 20 & 30.8 & 0 & 0 & 0 & 0 \\
\hline Pause filler & 0 & 0 & 1 & 1.5 & 0 & 0 & 0 & 0 \\
\hline Total & 83 & 56.1 & 65 & 43.9 & 80 & 52.9 & 71 & 47.1 \\
\hline
\end{tabular}


Table 3. Frequencies/percentages and number of occurrences of the semantic formulas in SNPs and KNPs refusal.

\begin{tabular}{|c|c|c|c|c|}
\hline \multirow{2}{*}{$\begin{array}{l}\text { Semantic formulas } \\
\text { Performative }\end{array}$} & \multicolumn{2}{|c|}{ SNPs No \% } & \multicolumn{2}{|c|}{ KNPs No.\% } \\
\hline & 0 & 0 & 5 & 1.6 \\
\hline Non-performative statement ("No") & 0 & 0 & 39 & 13.1 \\
\hline Negative willingness/ability & 31 & 8.2 & 19 & 6.4 \\
\hline Statement of regret & 28 & 7.4 & 54 & 18.1 \\
\hline Wish & 2 & 0.5 & 1 & 0.3 \\
\hline Excuse, reason, explanation & 109 & 29 & 78 & 26.1 \\
\hline Statement of alternative & 7 & 1.9 & 3 & 1.1 \\
\hline Set condition for future or past acceptance & 10 & 2.7 & 2 & 0.7 \\
\hline Promise of future acceptance & 2 & 0.5 & 2 & 0.7 \\
\hline Postponement & 20 & 5.3 & 6 & 2.1 \\
\hline Criticism & 3 & 0.8 & 7 & 2.3 \\
\hline Statement of negative consequences & 13 & 3.5 & 7 & 2.3 \\
\hline Self-defense & 3 & 0.8 & 0 & 0 \\
\hline Let the interlocutor off the hook & 6 & 1.6 & 17 & 5.7 \\
\hline Ask for forgiveness & 42 & 11.2 & 1 & 0.3 \\
\hline Apology & 1 & 0.3 & 2 & 0.7 \\
\hline Request for understanding & 5 & 1.3 & 0 & 0 \\
\hline Swearing & 0 & 0 & 4 & 1.3 \\
\hline Define relation & 5 & 1.3 & 1 & 0.3 \\
\hline Using idiom & 2 & 0.5 & 3 & 1.1 \\
\hline Statement of positive opinion/feeling or agreement & 9 & 2.4 & 3 & 1.1 \\
\hline Statement of empathy & 15 & 3.9 & 3 & 1.1 \\
\hline Gratitude/appreciation & 58 & 15.4 & 41 & 13.7 \\
\hline Pause filler & 0 & 0 & 1 & 0.3 \\
\hline Getting the interlocutor's attention & 5 & 1.3 & 0 & 0 \\
\hline Total & 376 & 55.7 & 299 & 44.3 \\
\hline
\end{tabular}

Table 4. Frequency of the semantic formulas in refusal of offers and requests by both SNPs and KNPs

\begin{tabular}{lcc} 
& Offers & Requests \\
\hline SNPs & 145 & 231 \\
KNPs & 148 & 151 \\
\hline
\end{tabular}

Table 5. Frequencies/and number of occurrences of direct, indirect, and adjuncts in KNPs and SNPs

\begin{tabular}{lcc}
\hline Semantic formula & KNPs No. & SNPs No. \\
\hline 1.Direct & 63 & 31 \\
2.Indierct & 188 & 258 \\
3.Adjunct & 48 & 87 \\
Total & 299 & 376 \\
\hline
\end{tabular}

"asking for forgiveness" at \%,11.2 (n=42) compared to only one of Kurdish counterpart.

\section{Gender Effect on Refusals Made by SNPs and KNPs Gender as Affecting the SNPs Refusal Strategies}

Concerning the SNPs all written refusal responses obtained from them resulted in (376) refusal strategies. SNP males used (162) refusal strategies at $(\% 43.08)$ while (214) refusal strategies were for females at (\%56.9). SNP males used 156 indirect strategies while (189) indirect strategies were used by females, these numbers and percentages indicate clearly that male and female participants adopted indirect strategies and adjuncts more than direct ones. This in turn indicates a similarity between them even the percentages of indirect strategies and adjuncts are relatively different. In addition, the findings of the present study suggest that politeness is realized differently by gender, although female participants 
used more refusal strategies than males, but some light should be shed on the point that males preferred less direct strategies. Thus, they use less impolite strategies than females. It is worth mentioning that the direct refusal "NO" never occurred in the refusal responses of the SNPs. Therefore, the performative direct refusal statement "I refuse" is avoided as well, and instead a variety of other strategies (indirect and adjunct) are employed to maintain politeness. This can go back to the effect of the Syriac communication nature which encourages indirectness in style to lessen the influence of refusals and avoid embarrassment. In other words, the participants in question have followed their refusals by excuses, reasons, or explanation in order to keep away from offending their conversant as well as to rationalize their acts of refusing. Besides, making various comments in refusing a situation indicates that the respondents realized that the longer the utterance, the politer they would sound.

\section{Gender as Affecting the KNPs Refusal Strategies}

The average of the data collected from Kurdish male and female participants implied that both groups were alike to an extent in using refusal strategies. Moreover, the findings of the current investigation show that politeness differ from the perspective of one gender to another, in spite of the fact that females used less direct strategies than males but on the other hand the male participants tended to be more indirect than females. In addition to this, females tended to be polite by using the word (رَيخن) instead of the word "No" (ن) , and mostly they added the adjunct of (Gratitude) with the direct of (non-performative) "No" to soften the effect of the word "No" and also to avoid embarrassment. Generally speaking, it can be concluded that Kurdish culture plays a great role in choosing the accurate strategies because culturally Kurdish people always try to provide the most soften answer for their interlocutors, by providing reasons/explanations and also by using regret so as to save the addressee from being offended. In addition to this, it is clear that the KNPs found the use of a variety of strategies as an opportunity to minimize the risks of face, as it is mentioned above that they tend to provide (regret/ reason/explanation/excuse) with most of the refusal strategies. Which in turn, can be used to keep a social harmony between friends and to enhance solidarity between the speaker and interlocutor. It can be concluded that there is something that cannot be denied that the culture and the gender differences had a great role in choosing the refusal strategies

\section{CONCLUSIONS}

From the analysis of the data, the study has come to several broad conclusions. Firstly, according to the results observed, all the strategies that were employed by both KNPs and SNPS were a mixture of direct, indirect, and adjunct. In addition, both KNPs and SNPs tended to use more strategies when refusing requests than offers. Secondly, SNPs used a greater variety of refusal strategies than the KNPs; SNPs totally employed 374 refusal strategies, while KNPs used 299 refusal strategies. Thirdly, there was a slight difference between the two genders of the KNPs in using refusal strat- egies, because both of them tended to use direct and indirect strategies more than adjunct ones.

The findings of the study, however, indicated that although females used less direct strategies than males, but, on the other side, the male participants tended to be more indirect than females. Regarding the SNPs, it was found that SNPs employed indirect and adjunct strategies more than direct ones. The findings also revealed that although females used a greater variety of strategies than males, but male participants employed less direct strategies than females. These evidences give us a clear understanding of the role of gender in using refusal strategies.

Finally, the culture of the participants of this study had played a vital role in the refusals opted. This notion proves that Kurdish and Syriac cultures have strong characteristics of collectivism, in which in group interests take priority over individual and protecting the harmony among group member is important. The participants adhere to strict, formal rules of behavior and politeness. For example, Kurdish participants used the direct "No" in their responses, therefore, this might indicate that they tend to risk of losing other's face when using such a strategy. Yet, their refusals are always lessened and justified by giving reasons, explanations and other indirect strategies such as gratitude/appreciation, and so on. For a Syriac speaker, good manners require that one never flatly refuse a request from a friend. This does not mean that the favor must actually be done, but rather that the response must not be stated as a definitive "no" or the performative "I refuse". If a friend asks for a favor, it should be done if possible. If the favor is unreasonable or too difficult, listening carefully, expressing doubt about the outcome and promising to help is appropriate. They feel obliged to come up with convincing and elaborated explanations for their refusals not only to save their own face but also to protect the face of others. For non-Syriac people, this might look like an exaggeration, insincerity and waste of time. But, for a Syriac speaker, considering other's face is essential.

The findings of the current study are applicable to those learners interested in increasing their knowledge of pragmatics in general and speech act of refusal in Kurdish and Syriac in particular. The study provides a useful path for those researchers working in discourse pragmatic studies as well. Moreover, the results of this study cannot be generalized to other contexts since in different contexts and under different conditions, the results might be different. So, the researchers suggest another replication of this study so that the importance of pragmatic competence specifically regarding speech acts increases.

\section{REFERENCES}

Abdul Sattar, H. Q., Che Lah, S., \& Raja Suleiman, R. R. (2010). A study on strategies used in Iraqi Arabic to refuse suggestions. The International Journal of Language Society and Culture, 30, 81-95.

Al-Eryani, A. (2007). Refusal strategies by Yemeni EFL learners. Iranian EFL Journal, 1, 84-101.

Aliakbari,M., \& Changizi, M. (2012). On the realization of refusal strategies by Persian and Kurdish speakers. International Journal of Intercultural Relations, 36(5), 659-663 
Al-Issa, A. (1998). Socio-pragmatic transfer in the performance of refusals by Jordanian EFL learners: Evidence and motivating factors. Unpublished Doctoral Dissertation, University of Pennsylvania.

Al-Kahtani, S. (2005). Refusal realizations in three different cultures: A speech act theoretically-based cross-cultural study. Journal of King Saud University, 18, 35-57.

Allami, H., \& Naeimi, A. (2011). A cross-linguistic study of refusals: An analysis of pragmatic competence development in Iranian EFL learners. Journal of Pragmatics, 43(1), 385-406.

Al-Shalawi, H. Gh. (1997). Refusal strategies in Saudi and American cultures. Unpublished Master's Thesis, Michigan State University, Michigan. Bardovi-Harlig, K., \& Hartford, B. S. (1991). Saying no in English: Native and nonnative rejections. In L. F. Bouton (Ed.), Pragmatics and language learning (pp. 41-57). Urbana, IL: University of Illinois at Urbana-Champaign.

Beebe, Leslie M., Takahashi, Tomoko, Robin, Uliss-Weltz, (1990). Pragmatic transfer in ESL refusals. In: Scarcelle, R.C., Anderson, E., Krashen, S.C. (Eds.), Developing Communicative Competence in a Second Language. Newbury House, New York, pp. 55--73.

Blum-Kulka, S., \& Olshtain, E. (1984). Requests and apologies: A cross-cultural study of speech act realization patterns (CCSARP). Applied Linguistics, 5(3), 196-213.

Chen, Xing, Lei, Ye, Yanyin, Zhang, (1995). Refusing in Chinese. In: Kasper, G. (Ed.), Pragmatics of Chinese as a Native and Target Language. University of Hawaii, Hawaii, pp. 119--163. Edmondson, Willis, 1981. Spoken Discourse: A

Félix-Brasdefer, J. C. (2002). Refusals in Spanish and English: A cross-cultural study of politeness strategies among speakers of Mexican Spanish, American English and American learners of Spanish as a foreign language. Unpublished Doctoral Dissertation, University of Minnesota, Minneapolis.

Félix-Brasdefer, J. C. (2003). Declining an invitation: A cross-cultural study of pragmatic strategies in Latin American Spanish and American English. Multilingua, 22(3), 225-255.

Félix-Brasdefer, J. C. (2006). Linguistic politeness in Mexico: Refusal strategies among male speakers of Mexican Spanish. Journal of Pragmatics, 38(12), 2158-2187.

Félix-Brasdefer, J. C. (2008). Politeness in Mexico and the United States: A contrastive study of the realization and perception of refusals. Amsterdam: John Benjamins

HAIG, G., \& YARON, M. (2002). Kurdish Linguistics:
A Brief Overview. Sprachtypologie und Universalienforschung, 3-14.

Khalil, A.R. (2014). A study of refusal strategies in Kurdish language. Kirkuk University Journal- Humanity Studies, 9(2), 17-39

Kwon, J. (2003). Pragmatic Transfer and Proficiency in Refusals of Korean EFL Learners. (Unpublished doctoral dissertation). Boston University, Boston, MA.

Lauper, J. A. (1997). Refusal strategies of native Spanish speakers in Spanish and in English and of native English speakers in English. In Paper presented at the annual meeting of the teachers English to speakers of other languages Orlando, FL.

Moheddin,K.R.,\&Mustafa,P.O. (2016). Invitation's refusal strategies in Kurdish. 2016(37).

Morkus, N. (2009). The realization of the speech act of refusal in Egyptian Arabic by American learners of Arabic as a foreign language. Unpublished Doctoral Dissertation, University of South Florida.

Nelson, G. L., Carson, J., Al Batal, M., \& El Bakary, W. (2002). Cross-Cultural Pragmatics: Strategy Use in Egyptian Arabic and American English Refusals. Applied Linguistics, 23(2), 163-189

Ramos, J. (1991). No. Because: A study of pragmatic transfer in refusals among Puerto Rican teenagers speaking English. Unpublished Doctoral Dissertation, Columbia University.

Sadeghi, K., \& Savojbolaghchilar, S. (2011). A comparative study of refusal strategies used by Iranians and Americans. International Journal of Academic Research, 3(2), 601-606.

Searle, J. (1969). Speech Acts. Cambridge University Press, Cambridge, England.

Searle, J., and Daniel, V. (1985). Foundations of illocutionary logic. Cambridge, England: Cambridge University.

Stevens, P. (1993). The pragmatics of "No!": Some strategies in English and Arabic. Ideal, 6, 87-112.

Stevens, Paul B., (1993). The pragmatics of "No!": some strategies in English and Arabic. IDEAL, 6, 87--110.

Woodard, R. (2008). The ancient languages of Syria-Palestine and Arabia. Cambridge: Cambridge University Press. 


\section{APPENDIX}

Appendix A. Kurdish Alphabets by Salavati and Esmaili (2013)

\begin{tabular}{|c|c|c|c|c|c|c|c|c|c|c|c|}
\hline No. & 1 & 2 & 3 & 4 & 5 & 6 & 7 & 8 & 9 & 10 & 11 \\
\hline Arabic-based & 1 & ب & 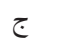 & ض & د & ی & ف & b & $\dot{j}$ & ك & J \\
\hline Latin-based & $\mathrm{A}$ & B & $\mathrm{C}$ & Ç & $\mathrm{D}$ & $\hat{\mathrm{E}}$ & $\mathrm{F}$ & G & $\mathrm{J}$ & $\mathrm{K}$ & $\mathrm{L}$ \\
\hline No. & 12 & 13 & 14 & 15 & 16 & 17 & 18 & 19 & 20 & 21 & 22 \\
\hline Arabic-based & s & ن & وَ & $\dot{ث}$ & ق & J & س س & ش & $ت$ & وو & ظ \\
\hline Latin-based & M & $\mathrm{N}$ & $\mathrm{O}$ & $\mathrm{P}$ & Q & $\mathrm{R}$ & S & Ş & $\mathrm{T}$ & $\hat{U}$ & V \\
\hline No. & 23 & 24 & 25 & 26 & 27 & 28 & 29 & 30 & 31 & 32 & 33 \\
\hline Arabic-based & $\dot{\tau}$ & j & ئ & g & & $\ddot{0}$ & 2 & J & $\varepsilon$ & $\dot{\varepsilon}$ & $\tau$ \\
\hline Latin-based & $\mathrm{X}$ & Z & I & $\mathrm{U} / \mathrm{W}$ & $\mathrm{Y} / \hat{\imath}$ & $\mathrm{E} / \mathrm{H}$ & (RR) & - & (E) & (X) & (H) \\
\hline
\end{tabular}

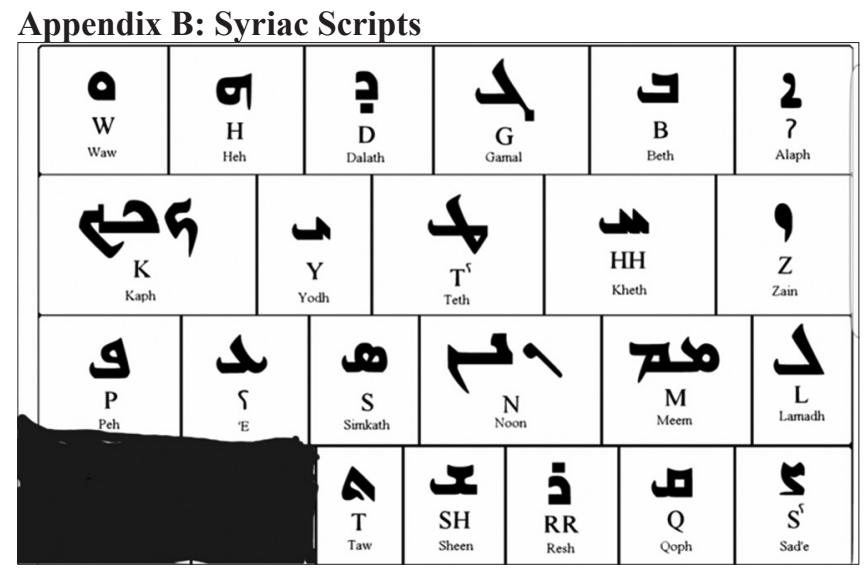

\section{Appendix C: The Syriac Version of the WDCT}

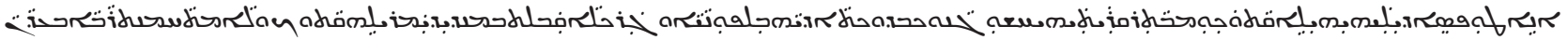

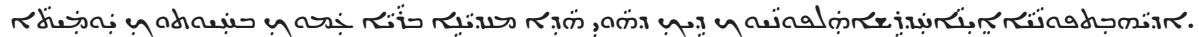

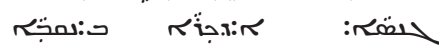

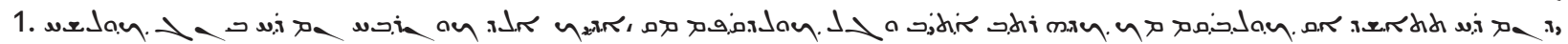

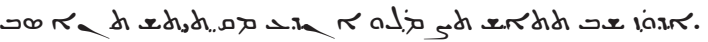
גت̈:

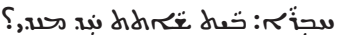

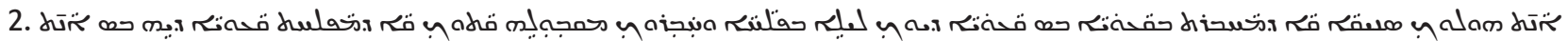
ג䧄.

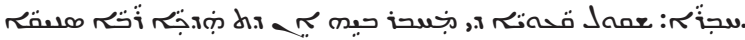
dت̈:

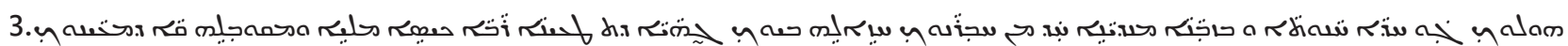

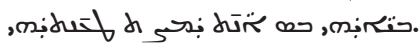

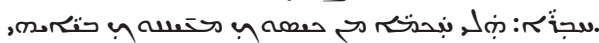
dॄ̈:

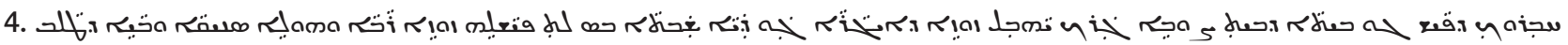

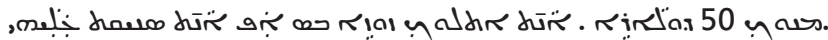

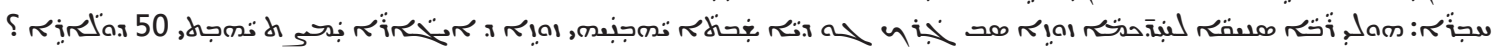
dॄ̈:

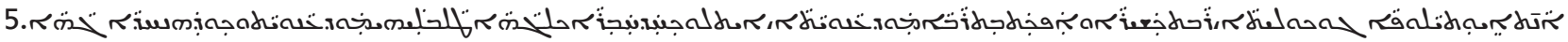
(uiَ.

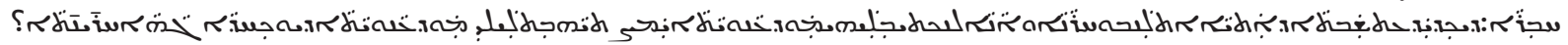
dü:

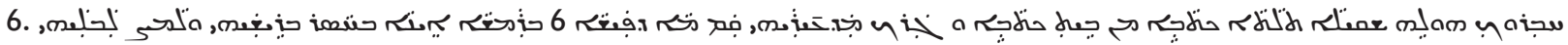




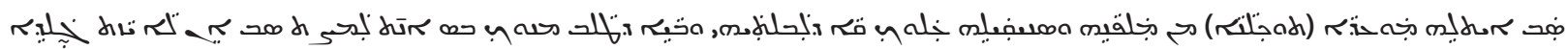

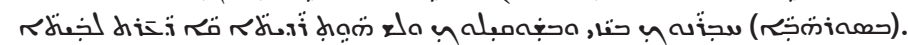

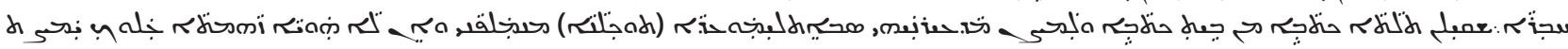

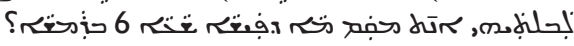
dire:

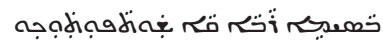

\section{Appendix D: The Kurdish Version of WDCT}

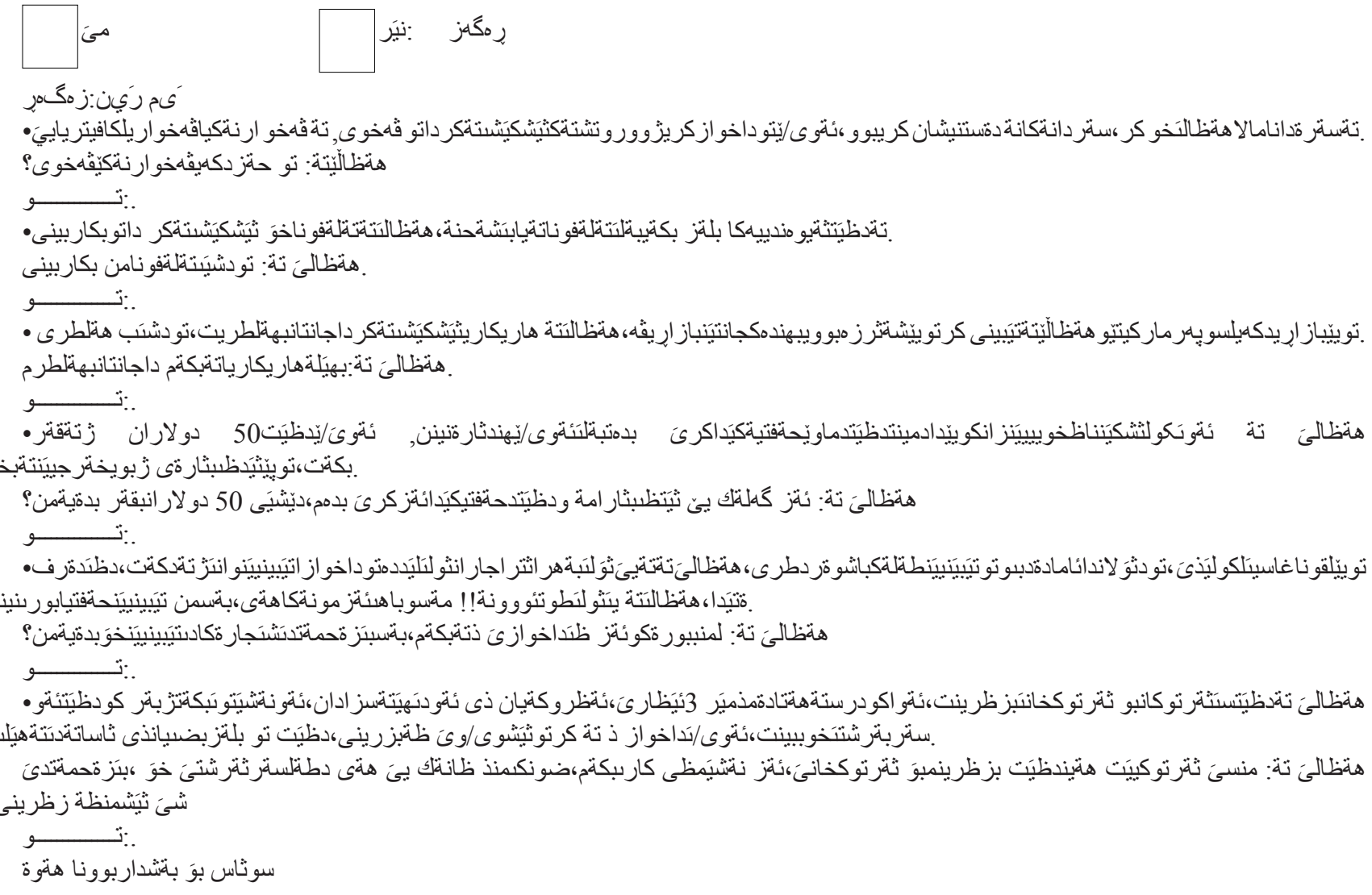

\section{Appendix E: The English Version of WDC Discourse Completion Task Please circle and answer:}
1. Gender:
a: male
b. Female

1. You visit your friend's home. It is unannounced visit. He/she invites you in and offers you something to drink. You have just had a drink at the refectory.

Your friend: Would you like to have a drink?

You:

2. Your friend has a free ticket to the movies but he/she is unable to at-tend. He/she offers to give the ticket to you. At the moment you do not have time because you have a lot of assignments to do.

Your friend: I have a free ticket to the movies. Would you like to go?

You:

3. You are shopping at the supermarket and your friend notices you are struggling with several bags of shopping. Your friend offers to assist you to carry the bags. You can handle them.

Your friend: Let me help you to carry the bags.

You:

4. Your friend who is staying at the university accommodation has to pay the rent within a week but he/she does not have enough money. He/she wants to borrow $\$ 50$ from you. You need the money for your own expenses.

Your friend: I am broke and have to pay the rent in a week. Can you lend me $\$ 50$ ?

You:

5. You drive a car. You come to your class farewell party at the university. One of your friends asks you to drive him/her 
home. Your car is full of other friends and there is insufficient space.

Your friend: Can you give me a ride home?

You:

6. Your friend has to return three books to the library which is due at $6 \mathrm{PM}$. today otherwise he/she will be fined. He cannot make it because he/she has to see his/her supervisor. He/she asks you to return them for him/her. You have to take your mother to see a doctor.

You:

Your friend: I have got three books to return to the library, I cannot do so because I have an appointment with my supervisor. You:

Can you please return them for me?

Your friend: Well!!

Thank you for your contribution 